1. To introduce new methods-such as putting in zippers, making pie crust, cooking various cuts of meat, deep fat frying, etc.

2. To teach use of equipment-electric stoves, pressure sauce pan, etc.

3. To emphasize the importance of using good techniques and giving the classes a chance to observe experts at work.

4. To show the production of various foods and manufactured products in order to have a background for using and appreciating the products.

5. To emphasize the importance of good nutrition by showing the results of both good and bad nutrition.

6. This teacher uses films and filmstrips on: food preparation, nutrition, consumer education, etiquette, budgeting, home decoration, and background for gracious living.

She also uses posters, charts, pictures, exhibits (both pupil and commercial), demonstrations, bulletin boards, and the chalk board.

Our English teachers use audio-visual aids in their various activities. Many available films are used at the time the topic, individual, or period is being stud. ied. A program has been developed so that unnecessary repetition does not take place. Records are being used which are usually in the voice of the author or of some outstanding actor or actress. Bulletin boards are used to display student work.

Maps and charts find their places in this area. Scrapbooks are made by the students on the various parts of literature. Dramatization, panel discussions, and original writing come in at the proper times. The tape recorder is used by this department in a very effective manner.

In closing, I want to point out that the teacher is probably the most important audio-visual aid of all. If the teacher is pleasing to look upon and pleasant to listen to and if this teacher possesses the various traits of character and culture and is properly trained so as to stimulate purposeful activity on the part of those. she teaches, then the other materials about which I have been talking are likely to fall into their proper places in the instructional program which she directs.

\title{
HOW MAY WE MAKE THE RECORDING AND REPORTING OF PUPIL ACHIEVEMENT MORE MEANINGFUL?
}

Chairman: Raymond A. Green, Principal, Newton High School, Newtonville, Massachusetts

INTERROGATORS AND CONSULTANTS:

I. Owen Foster, Associate Professor of Education, Indiana University, Bloomington, Indiana

Ernest A. Payne, Principal, Chaffey Union High School, Ontario, California

\section{Summary of a presentation by LAWRENCE E. VREDEVOE}

\section{$\mathrm{T}$}

HIS report is based upon personal interviews during the past four years with administrators and teachers in 328 schools, 300 parents of elementary- and secondary-school pupils, 200 elementary- and secondary-school pupils, and 100

Lawrence E. Vredevoe is Director of the Bureau of School Services, University of Michigan, Ann Arbor, Michigan. 
high-school graduates. An attempt was made to determine the attitudes, desires, and reactions of pupils, parents, and teachers to the methods of reporting used by their schools and to discover from school representatives what determined the method they were using. It is my desire to present the general conclusions and overtones derived from these interviews. At a later date the detailed summary of the data may be published.

This study revealed that no part of the program of communication with parents is of greater importance or influence than that which attempts to report achievement, growth, or progress of the individual pupil in school. School off. cials can be assured that any written report of this nature will be carefully examined, discussed, and considered. From these reports, many parents and pupils form their likes or dislikes for individuals, parts of the program, or the entire school. Reporting which is recognized as fair and understood by parents and pupils usually results in good school and home relations. That which is misunderstood or considered unfair develops barriers to school support.

The following statements of parents who were interviewed reveal how the attitude toward the school is directly or indirectly related to pleasant and unpleasant experiences with the reporting system. One of the interviewed persons said, "When I received my daughter's report, I lost all faith in our schools. I dropped my PTA work and quit going to meetings."

A father said, "How can schools expect our support when they show how little they know about our kids by their reports."

A mother said, "I am amazed how well they have analyzed my son's good and bad points. When I went to school, we only received grades."

A PTA president said, "We hope to throw out that new marking system at our next meeting of the board of education. Maybe later we can also throw out some of those who introduced it."

Reports from schools were directly blamed for runaways from two homes, attempted suicide in one case, parental dissension in six cases, and in other cases, corporal punishment and illness. The influence of the schools' reports on the pupils should not be underestimated.

The interviews with administrators and teachers revealed that:

1. More time had been spent in faculty and group discussions on "how to report" rather than "what to report." "How to evaluate competence, growth, or progress" took second place in the time given for study and discussion of "how shall we report."

2. The marking with symbols of $A, B, C, D, E$, or their equivalent was the practice by almost all secondary schools. In the primary grades there was a definite trend to provide other methods. Elementary schools used letter grades in the upper classes as part of their reports or permanent records.

3. The value of the letter grades differed from school to school and among teachers within the same school. 
4. Most schools do not periodically review the standard of work symbolized by each letter grade. The use of number grades did not eliminate the wide differences in marking because of the variations in teachers' standards.

5. Many teachers differed in their interpretation of achievement. Within some schools, achievement was determined by comparing the individual progress of the pupil to other pupils in the same grade in the city, state, and nation, whereas other teachers determined the progress the student has made in relation to his own ability and effort.

6. The use of only two marks such as " $S$ " for "Satisfactory" and " $U$ " for "Unsatisfactory" did not solve the problem of reporting. Plus $(+)$ or minus $(-)$ were attached to the " $S$ " and the " $U$ ", indicating a desire on the part of the teachers to have a wider range in grading.

7. Letter grades generally do not represent a numerical scale but an abbreviated scale for: $\mathrm{A}$-excellence; $\mathrm{B}$-superior or above average; $\mathrm{C}$-average; $\mathrm{D}$ below average; and E-unsatisfactory or failure. These words were frequently found in the reports in those schools where letter grades were being eliminated. The addition of the plus or minus to the " $U$ " and " $S$ " was evidently serving the same purpose by providing six categories instead of the two arbitrary categories of passing and failing.

8. In many instances, secondary-school personnel justified the need for letter grades because of college entrance requirements. Elementary schools justified it because of secondary-school requirements.

9. There is as much danger in reporting too much as too little.

10. Letter grades will remain as part of the reporting methods by secondary schools for some time in spite of their limitations.

11. The use of more elaborate forms of reporting gradually becomes less popular unless faculties review the purpose of the system they use. Marking a checklist or sending additional information home with the grades becomes less popular with teachers after a period of time. In thirty-eight schools some of the teachers reported nothing more than grades although checklists were provided.

12. Personal conferences with parents at school penalize those who lack transportation, work outside the home, have others to take care of in the home, or lack the social confidence to appear at school. Pupils in secondary schools discourage their parents if they feel that they do not measure up socially. The lack of time and suitable conference rooms were also given as barriers to this type of reporting.

Personal interviews were preferred on the elementary level, whereas parents recognized that high-school pupils prefer to handle their own problems because they like to feel grown up. Pupils of this age group like to keep mother and father away from school in many instances because they are concerned about approval or disapproval by fellow students.

The general attitude of parents could be summarized as a desire to have something definite to indicate pupils' achievement. They also want additional infor- 
mation about their child. They want to know about his work habits, his ability to get along with the group, and how he compares. with others of his age group in other schools. Furthermore, parents are interested in knowing "why" something is happening to their child.

Pupils, who were interviewed, indicated that they believe they know the reasons for poor grades. They emphasized a need for a greater degree of fairness in a marking system and more opportunity to discuss their reports with their teachers.

Schools should be frank in indicating to the parents that they have no accurate method of evaluation.

Suggestions for improving the methods of reporting are:

1. Careful evaluation of what you are trying to report as well as how to report.

2. Agreement and understanding of the system used by all faculty members.

3. Development of a method of reporting whereby the teacher can give more information without consuming too much time and doing endless clerical work.

4. Developing a better understanding of the program of marking by parents and pupils.

5. Recognition that one system of reporting is not satisfactory on all age levels.

6. Consistency in the standards used by the teachers to determine the grades.

7. Research in the growth and development of children.

8. Greater study of the problem of human relations by faculty members.

\section{Summary of a presentation by CHARLES P. LINDECAMP}

$\mathrm{T}$ INTEREST IN THE PROBLEM

L HE importance of this question to secondary-school principals is emphasized by the fact that the general topic appears repeatedly on the agenda of our annual conventions. At the Thirty-Sixth Annual Convention in Cincinnati, a very profitable discussion developed on the topic "How Should the Secondary School Evaluate and Record Student Progress?" As a result of that discussion and the publication of the presentations in THE BULIETIN, requests for copies of the definition of school marks and the report form used in Garfield Heights High School were received from many high schools in nine different states. Also as a direct result of that discussion, I had the privilege of serving as a consultant in a county-wide workshop on evaluating, recording, and reporting where more than one hundred teachers and administrators showed keen interest, not only in the theoretical discussion of the problem, but more directly in "down to earth" material, something tangible, something of immediate value which can be used now to start a program of improvement.

Charles P. Lindecamp is Principal of Garfield Heights High School, Cleveland, Ohio. 
While we have been studying the problem for years and will be studying the program for many more years there are no easy answers. We need to provide opportunity for small groups to talk and study.

\section{WHAT ARE WE RECORDING AND REPORTING?}

It seems essential to raise this question if we are to understand how to make the records and reports more meaningful. It is very probable that we are reporting and recording principally the results of subjective measurement. If we depend upon actual measures, we must depend upon something tangible, something that we can prove to parents and to the public.

In reading some recent writings I find this quotation: "Ralph W. Tyler says that teachers need psychological security. They devote their time to memorization work because it is tangible. It is tangible because they can measure it. Their purpose is clear, their public relationships are good, they avoid criticism and are at peace with the world." 1

Harold Alberty, professor of education, Ohio State University, recently stated: "I feel certain that our present problem is to develop the best curriculum possible and then see what we can do to evaluate it. After all, subjective judgments prevail in almost all fields of endeavor, and we do not get along so badly. The quest for objectivity had its inception in the concept-false, I think-that whatever exists, exists in some amount and can be measured. That concept almost wrecked education in the late twenties and thirties."

In this discussion we cannot consider the various objective devices used to help arrive at the recorded and reported marks. In the final analysis in practical everyday situations, teachers must rely upon subjective measurement if practical, workable, understandable records are to be made and reported to the homes. Therefore, our problem is to develop a system of recording and reporting that will be most meaningful in meeting the purposes of our records and reports of pupil progress.

\section{WHY DO WE KEEP RECORDS AND MAKE REPORTS?}

The purposes of records are classified by Yeager $^{2}$ in this way:

1. The legal basis-information needed under state laws

2. Archival purpose-information needed for promotion, transfers to college or another school, survey needs, work permits, etc.

3. Attendance enforcement

4. Guidance-data peculiar to each individual

5. Reporting to the home

6. Pupil progress

${ }^{1}$ Charles J. Lindecamp, "Evaluation in the Core Curriculum" Paper, Ohio State University, 1952.

2William A. Yeager, Administration and sbe Pupil, New York: Harper and Brothers, 1949. 
The last two purposes concern us here. The sixth is the most important, although the others have very necessary functions in present-day educational organization. Pupil progress involves admission, classification, promotion, and the extent to which the pupils are meeting the objectives of the educational philosophy of the school according to the opinions of those determining the recording of the record.

Our chief problem then seems to be how to record the progress of pupils and report that progress to the home so it will be most meaningful in developing real American citizens. A record is of little value unless it is put to use and reporting is one of the uses.

\section{CARDINAL PRINCIPLES IN REPORTS}

It is my considered opinion that the following points should serve as a guide in recording pupil progress and reporting pupil progress to the homes:

1. There should be some understandable uniformity in the reports for all twelve grades.

2. Give definite marks. A general statement is not enough.

3. Keep the report system as simple and plain as possible to avoid confusion and disagreement and so parents can understand the system.

4. Include subject marks and some indication of basic habits and traits as clues to the degree of success.

5. Use commendatory comments if any comments of a critical character are to be included.

6. Think in terms of an appraisal of pupil achievement rather than in terms of an accurate measurement.

7. Space the reporting periods far enough apart to lessen the laborious work for teachers. Reports have often been condemned because this is the biggest clerical work the teacher has to perform. Make the periods frequent enough to maintain active pupil and parent interest.

8. Define the marks used.

\section{- PLAN IN ONE HIGH SCHOOL}

Below, in brief, is the recording and reporting system used in Garfield Heights High School, developed after extensive study which is described in the March, 1952, issue of THE BULLETIN:
A equals 5 points-Superior (Honor Grade)
$B$ equals 4 points-Good (Above Average)
C equals 3 points-Average (Average)
$\mathrm{D}$ equals 2 points-Poor (Below Average)
E equals 1 point -Failing (No Credit)

The description in parentheses was added to make an understandable correlation between the elementary reporting system and the high-school system. The following additional checklist showing development in basic needs, or traits needed for effective living, which may give clues to the reasons for the letter 
marks assigned and suggest approaches toward improvement, is included on the home report cards.

Specific Work Habits

Participation in class

Use of study time

Accuracy
Adjustment witb Otbers

Co-operation with others

Leadership

Thoughtfulness
Bebavior Traits

Dependability

- Initiative

Courtesy

Items marked with a check mark are commendable, and those with an " $\mathrm{X}$ " are in need of attention. Identical headings are included on the permanent record folders. To comply with point eight under cardinal principles of reports, a mimeographed sheet defining the school marks is sent home at the end of the first reporting period. The reverse side of the individual class report cards has space for teacher comment, parent comment, and parent signature. One teacher recently gathered some interesting data relative to the effect of commendatory reports. Thirty per cent of the cards carrying excellent and good comments by the teacher brought "parent comments," while six per cent of those with critical comments brought parent response.

\section{CONCLUSION}

This system of recording and reporting, described briefly above, seems to be meeting the objectives of the school where it is used. These objectives are written in detail in each teacher's manual which, briefly stated, mean the development of citizens trained to live and to love the American, democratic way of life. A more detailed system of objective reports would tend to defeat that purpose. It is my opinion that a plan of recording and reporting, with five letter grades with point equivalents, with provision for a few simple checks on citizenship development, is a decided step forward which has come during the experience of many of us now engaged in training youth. I believe it is meeting our needs to a very adequate degree because it parallels life situations.

We should always strive for better recording and reporting systems to improve gradually; the method described, which is now very widely used with minor modifications, but, until a better method is developed, education will be promoted and youth better served by a more uniform use of a five-letter system with point values.

It is all to the credit of our profession that we give our best efforts to improvement. We meet to criticize our methods. So it will probably be different when I say that I believe we are doing better with recording and reporting pupil progress than literature indicates. In our professional desire constantly to improve this basic phase of the school program, we are likely to lose sight of the splendid progress already made and the evidences we see throughout the nation of progress to come. 